\title{
On the Cultural Meaning of Anyi Ancient Village Folklore and Woodcarving Art
}

\author{
XiaoYun $\mathrm{He}$ \\ Jiangxi Vocational Technical College Of Industry \& Trade, Nanchang, Jiangxi, China, 330038 \\ 3107000933@qq.com
}

\begin{abstract}
In our country, the folk style of the southern region and the northwest region is very different, and this is mainly because the geographical location of the southern region and the northwest region is different, the different geographical location will give birth to different cultures, and the cultural background will produce different people, because people are social animals, the society here does not refer to the sum of the relationship between all people and people, but refers to the environment that people live in the same background together, so people are created by the society and will also follow the needs of the society. Therefore, the folk culture of a region can understand the cultural background of a region through the folk culture of a region, and the main circle of this text also understands the cultural background of a region. To study and discuss the cultural details of ancient village folklore and woodcarving art.
\end{abstract}

Keywords: Anyi ancient village folk custom; woodcarving art; cultural details

\section{浅谈安义古村民俗与木雕艺术的文化意蕴}

\author{
何小云
}

江西工业贸易职业技术学院，南昌，江西，中国，330038

3107000933@qq.com

\begin{abstract}
摘要
在我国，南部地区和西北地区的民间风格有着非常大的差异，而这主要是因为南部地区和西北地区的 地理位置不同，不同的地理位置会孕育出不同的文化，而文化背景又会造就出不同的人，因为人是社 会性动物, 这里的社会并不是泛指所有人与人生活的关系的总和, 而是指在同一背景下生活的人与人 共同构建的环境，所以人是由社会打造，也会跟随社会的需求而改变，因此，通过一个地区的民俗文 化就能够了解一个地区的文化背景, 而本文也主要围绕安义古村民俗与木雕艺术的文化底蕴进行研究 和探讨。
\end{abstract}

关键词：安义古村民俗；大雕艺术；文化底蕴

\section{1 安义古村人的民俗文化}

在江西, 能够体现出江西特色文化和商文化的地方 非安义古村莫属, 首先, 安义古村作为古村群之一, 在 外观上充分满足了 “古朴” 这两个字的需求, 同时, 安 义古村也满足了人们对过往生活的想象。从安义古村去 往万寿宫, 需要途径古罗田, 而四面八方的旅人都会特 地赶到万寿宫进行朝拜, 所以古罗田成为了一块非常繁 华的区域, 在古罗田还依稀可见当年的风采, 虽然人们 现在再前往古罗田, 已经不能再看到曾经热闹繁华的模
样, 但是古罗田的基本构造还是没有变, 人们在麻石板 上还能看到岁月齿轮碾过的痕迹。而同时，过去的人们 的智慧也是令人无法想象的，虽然现在科技发达，人们 已经体验到了很多便利, 但是在过去, 没有计算机技术 的时代, 没有高科技的时代, 人们还能够在街道下面安 置排水系统, 这是何等的智慧。

在过去, 宗教活动盛行, 尤其是道教和佛教, 香火 不断, 而在安义古村, 也有道教和佛教的踪影, 仿佛往 年的香火气息还弥漫在人们的周围，有待考证的是，旅 人前往万寿宫时，都会特意到安义的 “逍遥观” 进行朝 拜, 所以也因此而催生了赣商文化。类似于现代的好风 景带动旅游业, 旅游业带动地区经济。就在这条前往“逍 
遥观” 的小道上, 赣商文化和赣文化得以交融, 道教精 神和佛教精神仿佛为人们辟开了一条新的道路。而除此 之外, 安义古村的 “世大夫第” 有着别具一格的建筑风 格, 门椐上有三层石雕, 这三层石雕就意味着想要鲤鱼 跃龙门, 考取功名, 就必须得付出更多的努力, 也是在 激励人们为了追求自己的梦想要勇于拼搏。虽然 “世大 夫第” 的主人往后的子孙都没有几个考取了功名, 但是 也吃穿不愁, 成为了走南闯北的商人, 从某种意义上而 言，也算实现了鲤鱼跃龙门。

闺秀楼就建在余庆堂的后堂, 而闺秀是指有钱有势 的人家的女儿, 而闺秀楼指的是闺秀的秀楼, 因为在旧 时, 女子要学习刺绣和琴棋书画, 而秀楼不仅是闺秀学 习刺绣的地方, 也是学习琴棋书画的地方。而在余庆堂 后堂的闺秀楼则十分精美, 主要以木板建成, 从闺秀楼 的外观上看就能够感受到主人家对此的重视。而余庆堂 的窗扇上就雕刻着 36 条鱼, 意味着年年有余。据传闻, 闺秀楼的小姐虽然出生大户人家, 而旧时的人也大多听 从 “父母之命, 媒妁之言”, 只有父母点头同意, 才能 结成婚约, 但是她却不惧流言, 为追求自由而选择用抛 绣球的方式定终身。闺秀楼的这位小姐也许在百年前就 已然有了超前的自由意志, 敢为他人不敢, 用心火为自 己开路。

在我国传统的戏台中, 安义古村的古戏台都是非常 有特点的, 至今为止, 也有几百年的光阴流逝了, 但是 古戏台却依然带着旧时来过的气息, 人们靠着对古戏台 的建设风格和建筑技术的辨认, 来感受这股气息。而同 时, 端详古戏台, 也仿佛能够看到多少年前古村的人们 就这么坐在戏台下方, 为一出出好戏鼓掌, 也为一出出 好戏落泪。古村群的建筑风格和建筑特色所体现的不仅 是古村群人民的民俗习惯, 也是古村群人民对艺术的渴 望, 对生命以外的事物的追求, 而这份情怀也造就了安 义古村。

\section{表 1 安义古村人的民俗文化}

\begin{tabular}{|c|c|c|c|}
\hline 安义古村作 & 安义古村的 & 余庆堂的 & 古 村 \\
\hline 为古村群之 & “世大夫第” & 窗扇上就 & 群 的 \\
\hline 一, 在外观 & 有着别具一 & 雕刻着 36 & 建 筑 \\
\hline 上充分满足 & 格的建筑风 & 条鱼, 意味 & 风格 \\
\hline 了 “古朴” & 格, 门楣上有 & 着年年有 & 和 建 \\
\hline 这两个字的 & 三层石雕, 这 & 余。据传 & 筑 特 \\
\hline 需求, 同时, & 三层石雕就 & 闻, 闺秀楼 & 色 所 \\
\hline 安义古村也 & 意味着想要 & 的小姐虽 & 体 现 \\
\hline 满足了人们 & 鲤鱼跃龙门, & 然出生大 & 的 不 \\
\hline 对过往生活 & 考取功名, 就 & 户人家，而 & 仅 是 \\
\hline 的想象。从 & 必须得付出 & 旧时的人 & 古 村 \\
\hline 安义古村去 & 更多的努力, & 也大多听 & 群 人 \\
\hline 往万寿宫, & 也是在激励 & 从“父 & 民 的 \\
\hline 需要途径古 & 人们为了追 & 命, 媒妁之 & 民 俗 \\
\hline 罗田, 而四 & 求自己的梦 & 言”，只有 & 习惯， \\
\hline 面八方的旅 & 想要勇于拼 & 父母点头 & 也 是 \\
\hline 人都会特地 & 搏。 & 同意, 才能 & 古 村 \\
\hline 赶到万寿宫 & & 结成婚约, & 群 人 \\
\hline 进行朝拜 & & 但是她 却 & 民 对 \\
\hline
\end{tabular}

\begin{tabular}{|c|c|c|}
\hline $\begin{array}{l}\text { 所以古罗田 } \\
\text { 成为了一块 } \\
\text { 非常繁华的 } \\
\text { 区域, 在古 } \\
\text { 罗田还依稀 } \\
\text { 可见当年的 } \\
\text { 风采, 虽然 } \\
\text { 人们现在再 } \\
\text { 前往古罗 } \\
\text { 田, 已经不 } \\
\text { 能再看到曾 } \\
\text { 经热闹繁华 } \\
\text { 的模样, 但 } \\
\text { 是古罗田的 } \\
\text { 基本构造还 } \\
\text { 是没有变, } \\
\text { 人们在麻石 } \\
\text { 板上还能看 } \\
\text { 到岁月齿轮 } \\
\text { 碾过的痕 } \\
\text { 迹。 }\end{array}$ & $\begin{array}{l}\text { 不惧流言, } \\
\text { 为追求自 } \\
\text { 由而选择 } \\
\text { 用抛绣球 } \\
\text { 的方式定 } \\
\text { 终身。 }\end{array}$ & $\begin{array}{l}\text { 艺 术 } \\
\text { 的 渴 } \\
\text { 望, 对 } \\
\text { 生 命 } \\
\text { 以 外 } \\
\text { 的事 } \\
\text { 物 的 } \\
\text { 追求, } \\
\text { 而 这 } \\
\text { 份 情 } \\
\text { 怀 也 } \\
\text { 造 就 } \\
\text { 了 安 } \\
\text { 义 古 } \\
\text { 村。 }\end{array}$ \\
\hline
\end{tabular}

\section{2 中国传统木雕艺术概述}

木头作为一种用大自然孕育出来的具有生命力的 物体, 它拥有大自然的纯洁与淳朴的品性。而在我国原 始时期, 祖辈们的生活当中就已经运用到了木头, 例如, 钻木取火, 他们会就地取材, 利用木头生火以换取温暖。 然而随着时代在慢慢的发展, 木头不再仅仅是人们取火 的工具, 而是成为了一种艺术品。人们会以各种珍贵的 木头为原材料进行雕刻, 从而形成木雕。古人利用自身 的智慧, 以及双手创造了很多具有艺术价值的木雕作 品。而在漫长的历史发展过程中, 这种木雕作品就形成 了我国传统的木雕艺术。木雕作为雕塑当中的人一部 分, 它也是民间工艺的形式体现。但是在木雕艺术的发 展过程中, 还有大部分人对于木雕艺术还停留在传统的 思想观念上。而为了木雕艺术能够在我国得到高效的发 展, 所以木雕艺术一定要进行创新, 并且要摆脱传统的 观念形式。在如今的时代, 当代价值的体系已经取代了 传统的价值体系, 使文人儒雅文化的审美艺术转向了以 大众为主的审美文化, 并且无论是创作的主体, 还是创 作环境都发生了改变, 形成审美取向、审美风格以及选 题都会有不同的表现，而那种从灵魂上就与大自然相契 合的诗情画意, 现在已经不存在了。如今的创作主要是 以当代社会矛盾问题为主体, 描述着人们的生活现状。

弗洛伊德, 作为给中国现当代艺术打开了一扇门的 主人公, 他为心里能够得到解放而吹起了决定性的号 角。弗洛伊德的最大贡献是在于他打破了传统的心理 学, 建立了一种以本能和情感为主体的心理学, 并且提 出了人们在生活的过程当中必定会遭遇到挫折, 而人的 精神与情感也会在现实生活当中出现矛盾, 随着中国社 会不断的发展, 人们生活的矛盾也会不断的被呈现。人 
们与社会在发展当中不断存在的冲突, 都会在我国当代 艺术家作品当中体现出来。因此, 现当代艺术的审美大 多都是荒诞无谬的, 它并不是一种美的体现, 而是一种 对生活现实的焦虑, 对生活的绝望的情感表达。

由于中国木雕艺术从我国古代发展至今, 具有悠久 的历史。中国木雕艺术当中对于我国民族传统色彩的表 现也是非常强烈的。另外, 木雕艺术的工艺特点主要表 现在三点: 造型精炼、线条清晰、刀法熟练等。无论是 那个时代的木雕艺术, 它都能够有效的将我国的传统文 化融入到艺术当中, 从而表达出一种寓意, 同时也是借 用艺术的形式来诉说着一种情感。

木雕艺术作为我国文化艺术的珍宝, 是中国传统民 间艺术具有代表性的形式之一。木雕艺术通过特色的创 作方式来雕刻作品, 其中呈现出来的作品也是各有特 色。因此, 木雕艺术也已经成为了我国传统文化的一种 象征, 并且在传承中国传统文化的当中, 对于木雕艺术 的传承也是非常重要的。人们可以通过对当代时代的想 法, 以及对于我国传统文化的情感, 利用木雕艺术来进 行推广与宣传。我国木雕艺术在发展的过程中会不断的 以新艺术的形式作品出现在人们的眼前。然而对于木雕 艺术的内在精神以及文化寓意的宗旨, 却从未被改变 过。所以无论木雕艺术如何发展, 都会带有中华民族的 特色, 即使木雕艺术在当代以新作品的形式展现, 但是 他所表现的情感当中依旧有我国传统文化的特色精髓, 并且对于我国传统文化的内涵与寓意进行了更进一步 的领悟。从而将木雕艺术与中国传统文化有效的结合, 形成一种符合当代人们的审美观念的艺术形式。

表 2 中国传统木雕艺术概述

\begin{tabular}{|c|c|c|}
\hline 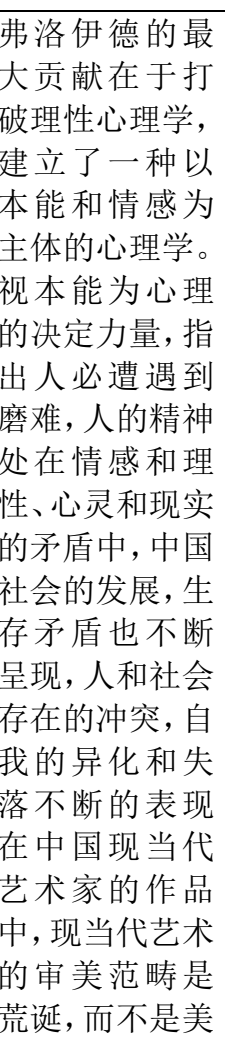 & $\begin{array}{l}\text { 海德格尔强调 } \\
\text { “贵真”, 庄子 } \\
\text { 固执地认为得 } \\
\text { 到 “意”之后, } \\
\text { 艺。中国木雕艺 } \\
\text { 术有比较悠久 } \\
\text { 的传统历史, 其 } \\
\text { 民族传统色彩 } \\
\text { 非常强烈。另 } \\
\text { 外, 木雕艺术的 } \\
\text { 工艺特点主要 } \\
\text { 有三点, 即造型 } \\
\text { 凝练、线条比较 } \\
\text { 清晰和明快、刀 } \\
\text { 法比较熟练和 } \\
\text { 流畅等。 }\end{array}$ & $\begin{array}{l}\text { 木雕工艺在中 } \\
\text { 国传统艺术文 } \\
\text { 化发展的过程 } \\
\text { 中具有很重要 } \\
\text { 的意义, 是中国 } \\
\text { 传统文化发展 } \\
\text { 的象征, 无论是 } \\
\text { 哪个历史时期 } \\
\text { 的木雕艺术, 都 } \\
\text { 已经融入了比 } \\
\text { 较有灵性的中 } \\
\text { 国传统文化本 } \\
\text { 源, 从而可以将 } \\
\text { 多种不一样的 } \\
\text { 寓意表达出来, } \\
\text { 同时诉说着不 } \\
\text { 一样的情感世 } \\
\text { 界。 }\end{array}$ \\
\hline
\end{tabular}

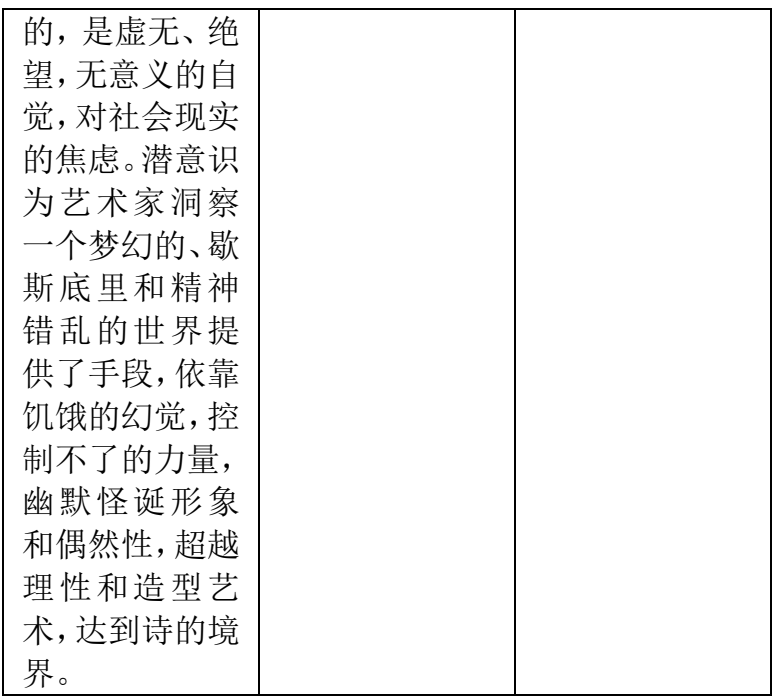

\section{3 安义古村木雕艺术的象征表意}

在我国, 木雕艺术的历史非常悠久, 而且造型百变, 主要分为浮雕和圆雕两种, 而浮雕和圆雕不仅是从名字 上看起来不同, 造型的差别也很大, 圆雕因为是圆形, 所以四面都可以看得非常清楚, 但是浮雕只能看到一 面。因为浮雕和圆雕的艺术需求不同, 但是相同的是, 浮雕和圆雕都体现了木雕之美，也体现了旧时人们对艺 术的追求。从实用角度来看, 浮雕和圆雕几乎不具备实 用性, 但是从美观角度来看, 浮雕和圆雕则是极佳的选 择。例如在余庆堂的窗扇上也雕刻了花鸟, 这些雕刻增 添了余庆堂的光彩, 也使余庆堂更加具有观赏性。而且, 这些雕刻都非常具有民间特色，从构图上看，也不止是 在追求平衡和美, 也体现了作者的审美和意图。而安义 古村的木雕就大部分采用的是具象的手法, 造型虽然非 常夸张, 但是在那些夸张的造型中也能够看出人物的神 态, 而这样的表现手法加强了木雕的质朴和明亮度, 也 较为追求意趣。如此一来, 观众在观赏木雕时, 就会将 重点放在木雕的形态上, 而且不由自主地被木雕所表现 的情绪所吸引。也由于木雕的场景和人物结合在一起, 所以可以轻而易举地为观众呈现出一个故事, 而不同的 场景和人物能够表现出的情节自然也存在差异, 因此主 要就要通过对木雕层次和图案的把握, 以及对线条的把 握来对木雕进行控制。在木雕中，任何一个细小的纹路 都有可能改变木雕所要呈现的图案和意思, 而木雕其实 也是写实艺术中的一种, 通过旧时古村民众对木雕艺术 的追求, 就能够看出旧时人们也在寻求精神领域的愉悦 和生活中的美。

就现阶段看, 水南村还遗留着将近三十栋的民居, 这些民居也许不如上文所提到的古戏台和余庆堂有气 势, 能从中突破历史的屏障, 受到几百年前的河流召唤, 但是民居有民居的特色，民居是最贴合旧时人民的居住 情况和居住环境的地方, 观察民居也是在观察旧时人们 的生活环境。而水南村遗留至今的民居上的雕花还非常 精致, 并且没有一样是重复的, 这也就意味着旧时民众 
对于美也有一定的需求, 而除了雕刻在窗户上的木雕非 常精美之外, 古屋中的雕饰也非常精美, 尤其是 “诗联 窗扇”，其中体现的不仅是古代艺术美，也是主人的文 化素养, 在诗中找情, 情中寻意, 如此想来, 旧时人们 的生活也是非常有情趣的, 甚至在某些时刻比起快节奏 的现代生活, 要更加使人愉悦和安心。在民居中也体现 了不少奇闻轶事, 虽然这些奇闻轶事目前已不可考, 但 是只当作一个故事来听, 也能解我们心头烦闷, 为我们 寻得一刻清净。

\section{4. 结语:}

安义古村作为江西非常有名的古村群, 其中体现的 不仅是几百年前的人文过往, 也是几百年前人们所追求 的艺术, 以及人们对自由意志的向往和传统生活中独属 于岁月的美。流转到今天, 安义古村自然也有了许多的 变化, 但是不变的是空气中弥漫的香火气息和脚下深深 的车轮印记, 这些是岁月留下的遗珠, 借予我们一窥时 光的影子, 在这些漫漫长夜中, 闺秀楼的小姐习琴棋书 画, 女工刺绣, “世大夫第” 的主人在油灯下奋笔疾书, 待天光大亮时, 又不知闺秀楼的小姐是否受得良人, “世 大夫第” 的主人又是否考取到了功名, 如今一切都成过 往, 只能借窗棂上的雕花和脚下的麻石板一探了。但是 无论如何, 在安义古村古村群的木雕艺术和民俗中的确 展现了其文化意蕴。

\section{References}

[1] Guili,Wangfei. A Study on the Application of Huizhou Woodcarving in the Liquor Museum[J]. Art and Design (Theory). 2019(05)

[2] Kaifeng Chu.techniques and arts in traditional wood carving techniques[J]. Journal of Shandong Institute of Agricultural Engineering. 2019(07)

[3] Yafei Xu. On Inheritance and Innovation of Woodcarving Art Form[J]. culture industry. 2019(09)

[4] Xuhong. Analysis on the Technology and Art of Woodcarving Technology[J]. culture industry. 2019(10)

[5] Chengxi, Minglei Zhang, Chuanshun Xiong. The persistence and inheritance of woodcarving families[J]. fellow worker. 019(09)

[6] Liping Yuan. Study on Confucian Connotation of Woodcarving Art in Yueyang Tower[J] 。 Journal of Yueyang Vocational and Technical College. 2019(05)

[7] Chen Xiayan. Wood carving art and Chinese traditional culture research [J]. Science and technology and enterprise,2013(23).
[8] Li Hui. An analysis of the cultural implication of Chinese traditional wood carving art [J]. Sculpture,2013(1). 